https://helda.helsinki.fi

\title{
Triggering factors in non-traumatic intracerebral hemorrhage
}

\section{Sallinen, Hanne}

2020-08

Sallinen , H , Putaala , J \& Strbian , D 2020 , ' Triggering factors in non-traumatic intracerebral hemorrhage ' , Journal of Stroke \& Cerebrovascular Diseases, vol. 29 , no. 8 , 104921 . https://doi.org/10.1016/j.jstrokecerebrovasdis.2020.104921

http://hdl.handle.net/10138/330639

https://doi.org/10.1016/j.jstrokecerebrovasdis.2020.104921

cc_by_nc_nd

acceptedVersion

Downloaded from Helda, University of Helsinki institutional repository.

This is an electronic reprint of the original article.

This reprint may differ from the original in pagination and typographic detail.

Please cite the original version. 


\title{
Triggering factors in non-traumatic intracerebral hemorrhage
}

\author{
Abstract \\ Background: In ischemic stroke and subarachnoid hemorrhage, there are known \\ preceding triggering events that predispose to the stroke by, for example, abruptly raising \\ blood pressure. We explored, whether triggering events can be identified in non- \\ traumatic intracerebral hemorrhage (ICH). \\ Methods: We used structured questionnaires to interview consented patients with ICH \\ treated in a tertiary teaching hospital, between 2014-2016. We asked of possible trigger \\ factors, including Valsalva-inducing activity, heavy physical exertion, sexual activity, \\ abrupt change in position, a heavy meal, a sudden change in temperature, exposure to \\ traffic jam, and the combination of the first three (any physical trigger) during the hazard \\ period of 0-2 hours prior to ICH. The ratio of the reported trigger during the hazard \\ period was compared to the same 2-hour period the previous day (control period) to \\ calculate the relative risks for each factor (case-crossover design).
}

Results: Of our 216 consented ICH patients, 97 (35.0\%) could be interviewed for trigger questions. Reasons for not able to provide consistent and reliable responses included lowered level of consciousness, delirium, impaired memory, and aphasia. None of the studied possible triggers alone were more frequent during the hazard period compared to the control period. However, when all physical triggers were combined, we found an association with the triggering event and onset of $\mathrm{ICH}$ (risk ratio 1.32, 95\% confidence interval 1.01-1.73). 
Conclusions: Obtaining reliable information on the preceding events before ICH onset was challenging. However, we found that physical triggers as a group were associated with the onset of ICH.

\section{Introduction}

Intracerebral hemorrhage (ICH), caused by a rupture of a brain artery into brain parenchyma, is the second most common form of stroke after ischemic stroke.[1] Approximately $40 \%$ of the patients die within one month, and many remain with major disabilities.[2] There is no effective medical or surgical treatment option, and those in clinical use are mainly supportive in nature, even though management in dedicated stroke units will likely reduce mortality and morbidity.[3] Several chronic risk factors such as hypertension, older age, and high alcohol consumption have been shown to associate with ICH.[4,5]

Apart from chronic risk factors, preceding triggering events that temporally predispose different types of stroke have been identified. For subarachnoid hemorrhage (SAH), triggering events that raise blood pressure temporarily, such as vigorous exercise, have been identified.[6,7] In a study of 390 patients with ischemic stroke, the risk of stroke was increased to 2.3 fold within 1 hour of moderate to vigorous physical activity.[8] In another study, outbursts of anger, and sudden change in body posture due to startling were found to trigger the onset of ischemic stroke, whereas heavy physical exercise, heavy meal, or sudden change in temperature were not.[9] Triggers such as sexual 
activity, straining at stool, exertion, coughing, and sneezing commonly precede thunderclap headache were also associated with reversible cerebral vasoconstriction syndrome (RCVS), a relatively rare condition that may lead to both ischemic and hemorrhagic stroke.[10]

Data on triggers of ICH are virtually lacking. We identified only one retrospective case series of $16 \mathrm{ICH}$ patients with various etiologies, investigating temporal relationship between ICH and sexual intercourse, with no case-crossover design or controls.[11] Optimally, the patient should be interviewed for triggers as soon as possible after the stroke to obtain reliable responses. The paucity of data in $\mathrm{ICH}$ perhaps originate indeed due to problems in obtaining information from the patients with $\mathrm{ICH}$, as they often have reduced level of consciousness, have communication barriers, and may have poor memory around the time of ICH.

In this study, we aimed to find out, whether examining triggering factors is feasible in $\mathrm{ICH}$ and whether such factors play a role in acute occurrence of $\mathrm{ICH}$.

\section{Materials and Methods}

This study was conducted in Helsinki University Hospital (HUH), Finland, between May 2014 and December 2016. Institutional review board and Ethics Committee of the Helsinki and Uusimaa Hospital District (11 December 2013 311/13103/01/2013 and 12 October 2016 HUS/1662/2016) approved the study. 
We aimed to prospectively recruit all consecutive patients with non-traumatic ICH. The inclusion criteria for the present study were non-traumatic ICH and informed consent given either by the patient or his/her proxy. Furthermore, the patient had to be awake when experiencing the first neurological symptoms and have a good level of consciousness, be vigilant and able to recall events immediately preceding the ICH at the time of interview. ICH caused by trauma, tumor, infarction, $\mathrm{SAH}$, vascular malformation, or other structural lesion were excluded.

The symptom onset time was defined as the time when the patient experienced the first symptoms attributed to ICH. We interviewed (H.S.) the patients with a structural questionnaire during their acute stay in hospital. The interview included potential trigger factors, which were actions causing Valsalva (lifting an object weighing over $20 \mathrm{~kg}$, having to strain when defecating/urinating, vomiting, coughing, sneezing, squatting for a long period of time), abrupt change in position, heavy physical exertion, a heavy meal, a sudden change in temperature, exposure to traffic jam and sexual activity. Physical triggers, i.e. factors that raise blood pressure abruptly (Valsalva-inducing activity, abrupt change in position, heavy physical exertion, and sexual activity), were further grouped for analysis. The hazard period was defined as 0-2 hours prior to the ictus, and as a control period was the previous day between the same time points. Each patient served as his/her control (case-crossover design). 
Additionally, we asked about feelings of anger in the same time periods. This question was included in a questionnaire that the patient filled in. The questionnaire was given upon recruitment, and if not returned, sent to the patient once more. The patient cohort having answered the questionnaire partly differs from the patients interviewed. Thus, the result regarding anger is shown in supplementary materials.

We used a combination of medical records and questionnaires to obtain the medical history. National Institutes of Health Stroke Scale (NIHSS), Glasgow Coma Scale (GCS), blood pressure, and other admission parameters were obtained from the patients' electronic medical charts. The size of the hematoma was calculated in the admission computed tomography $(\mathrm{CT})$. We used the $\mathrm{ABC} / 2$ method, where $\mathrm{A}, \mathrm{B}$, and $\mathrm{C}$ are the largest perpendicular measures of the hematoma on the images. Clinical deterioration was defined by increase in NIHSS by at least 4 points within 1 week of ICH.

Statistical analyses were made using SPSS v.24 (IBM, Armonk, NY). We express categorical variables as counts (\%), continuous variables with normal distribution as mean with standard error (SE), and continuous variables not normally distributed as median with interquartile range (IQR) values. The differences between the groups were calculated using the $\chi 2$ test, the t test, or the Mann-Whitney U test as appropriate. For trigger factors, the ratio of the reported potential trigger factor during the hazard period, compared to the same period the previous day was used to calculate the relative risks (RR) for each factor. The RR was calculated by the formula $(a+b) /(a+c)$, where ' $a$ ' is the number of patients with exposure in both periods, 'b' number of patients with exposure in 
the hazard period only, and 'c' number of patients with exposure in the control period only. The lower and upper limits of the $95 \%$ confidence intervals were calculated by a syntax for SPSS provided by IBM.

\section{Results}

Figure 1 depicts the number of patients interviewed, and patients returning the questionnaire. Of our entire cohort of $277 \mathrm{ICH}$ patients, 97 (35.0\%) were eligible for the

present study and able to provide consistent answers on the trigger questions. The reasons for ineligibility included lowered level of consciousness, delirium, impaired memory, aphasia, death, and quick transfer to another hospital. Depending on the question, 78-95 patients (80.4-98.0\% of the interviewed patients), could provide answers. The median delay between ICH onset and interview was 2 days (IQR 1-3), ranging from 0 to 14 days. For one patient the time of the interview was not recorded.

The comparison of the patients who were and who were not able to provide answers to the first seven trigger questions is shown in Table 1. Patients who could not provide answers had larger ICHs, higher admission NIHSS, and lower admission GCS. They were also older, had more often antiplatelet treatment, and their informed consent was more often given by a proxy. They were also more likely to deteriorate, undergo neurosurgery, and receive do-not-resuscitate (DNR) orders. In the follow-up at three months, patients who could not provide answers had higher mRS score and lower Barthel Index score, and they were less likely to live at home. 
The relative risks for the exposures of potential trigger factors during the 2-hour period preceding the ICH, compared to the same period the day before are shown in Table 2. None of the studied possible triggers alone, including anger, were more frequent just prior to the ictus, compared to the same time period the day before. However, when we combined actions causing Valsalva, physical exercise, and sexual activity as a physical trigger (i.e. factors that raise blood pressure abruptly), we found an association with the onset-time of ICH and the physical trigger (RR 1.32, 95\% CI 1.01, 1.73).

The question on actions causing Valsalva was the most difficult to answer, as the many of the actions included in the question are rather automatic — such as coughing — and the timing may go unnoticed and difficult to recall afterwards. Of the interviewed patients, 78 patients (80.4\%) could provide consistent answers on the Valsalva question. Valsalva, and heavy exercise were the most reported exposures during the hazard period. No patients reported change in position, such as startling in any of the periods.

\section{Discussion}

To the best of our knowledge, this is the first case-crossover study assessing the question whether triggering factors can be linked to the onset time of ICH. We found that a combination of physical triggers was associated with the timing of ICH. The effect was, however, relatively modest. The effect size may truly be small or the result may reflect difficulties in obtaining information from ICH patients on triggering events. 
From the methodological point of view, in case-crossover design each case serves as its control, being closely analogous to a matched pair-control design. The frequency of a certain exposure before a certain outcome is compared to the exposure frequencies during certain control times to calculate the relative risks for the exposure.[12] This design has been used in quantifying triggers before for example $\mathrm{SAH},[6,7]$ ischemic stroke, $[8,9]$ myocardial infarction,[13] and injuries.[14] The onset time should preferably be abrupt, and the studied trigger transient.[12] A single (as in our study the previous day at the same time point), or multiple control periods per case can be used.[15] Self-matching the subject serving as his/her own control - eliminates such confounding factors that are constant within the subjects, but would possibly differ between subjects in case-control studies. In case-control studies, the study period and control period are answered by different individuals, which may lead to different interpretation of the question. This problem is overcome in case-crossover design. A single time period allows matching of the hazard period and control period by for example by the time of day, as in our study.[15] However, in that setting, the possible effect of the day of the week on the prevalence of a certain event cannot be taken into account.

An observational study on $848 \mathrm{ICH}$ patients including also brain tumors and vascular malformations reported that $30 \%$ of the ICH appeared in rest, 50\% during light exertion, and 20\% during moderate/vigorous exertion.[16] Potential triggering events (such as strenuous exercise and the sudden transition from the supine to the erect position on awakening) were identified in $27 \%$ of the patients, being more common among ICH considered hypertensive, than among ICH considered secondary or undetermined. Comparison with other time points or controls was not made. 
A study on SAH found that drinking coffee or cola, vigorous physical exercise, nose blowing, straining for defecation, being startled, anger, and sexual intercourse before the rupture of an aneurysm served as trigger factors to the hemorrhage, with increased relative risk compared to the patients' usual frequency of exposure. They observed that the relative risk differed between the site and size of the aneurysm. In a subgroup analysis, most of the increased relative risks were already visible in subcohorts of as small as 50 to 70 patients.[7] Another study in SAH patients with a case-crossover design also demonstrated 2.7-fold increase in the rupture risk of the aneurysm during the 2 hours following moderate to extreme physical exercise.[17]

In a study on potential trigger factors in the context of ischemic stroke, negative emotions were the most common trigger during the 2-hour period before stroke onset, reported by $14.5 \%$ of the 200 patients. Additionally, anger, sudden posture change due to startling were associated with the onset time, whereas temperature change, positive emotions, heavy eating, and physical exercise were not.[9]

However, the mechanisms of ischemic stroke and ICH differ - one caused by an occlusion, and the other by a rupture of an intracerebral artery. Thus, the mechanisms of the triggering actions on the onset of the ictus are likely different. Many of the studied triggers have been shown to cause a sudden rise in blood pressure.[18-21] It would be reasonable that abruptly increased blood pressure may lead to a rupture of an already weakened vessel wall. In our study, we demonstrated that actions leading to rapid and short-lasting rise in blood pressure associate with the timing of $\mathrm{ICH}$. Additionally, 
possible considered mechanisms how the trigger factors increase the risk for cardiovascular events have been the physiological effect on blood pressure, heart rate, myocardial oxygen demand, which are at least in part mediated by cathecolinamine secretion.[22,23]

We could not identify any of the tested potential trigger factors alone to trigger the onset of ICH in our cohort. It is likely that our sample size is too small to show small increases in relative risks, however, in subgroup analysis of SAH patients similarly small as our cohort, the relative risk increases for many of the triggers could be seen. Thus, it is possible that the increase in the relative risk after the triggering event would be smaller in $\mathrm{ICH}$ than in SAH.

The strength of our study is using case-crossover design, leading to no selection bias for control selection. In contrary to the previous studies in SAH patients, [6,7] the patients were interviewed face-to-face for most questions instead of having to fill in the questionnaires themselves. Thus, during the interview, we were able to evaluate, whether the patient was able to provide consistent answers and had sufficient level of orientation. We did not rely on information by proxy - few proxies would be assumed to be able to provide reliable answers on such personal questions. Due to the nature of ICH and its frequent neurological and medical complications, many patients were not able to be interviewed and answer the questions due to their neurological deficits such as aphasia, lowered level of consciousness, or disorientation. Thus, the patients not interviewed were more severely affected, with larger ICH volumes, higher NIHSS, and lower GCS. 
Studies on myocardial infarction have considered the effect period for e.g. sexual activity[24] and anger[22] as $\leq 2$ hours, and for exertion $\leq 1$ hour,[13] and another study suggested the elevated risk remaining 45 minutes after stopping exertion.[25] The hazard period in our study was defined as 0-2 hours before the ictus for all of the questions in order not to miss actions possibly relevant, and to make answering the questions as simple as possible for the acutely ill patients. We ruled out patients with unknown ICH symptom onset, but obviously, some level of uncertainty regarding the exact timing of the potential triggering events remain. Additionally, we cannot rule out the effect of recall bias, as the patients may more readily remember events occurring the day of their ICH than before. Therefore, we chose the same time at the previous day, as opposed for example a week ago, or multiple time periods, to reduce the recall bias. Recall bias may also differ between questions, as the individuals may recall better events considered significant, or events occurring every day at the same time. Individuals may also report more readily actions considered healthy or desirable, such as vigorous exercise than for example outbursts of anger.[15] The limitations of the study include the small cohort only $35 \%$ of the whole cohort of recruited patients being able to provide answers for this substudy. During questioning, the exact time points of the specific events were not recorded. Additionally, due to the small number of patients, sensitivity analyses using different time points could not be made. The grouping of the physical triggers as a single parameter was done after analyzing each of the physical triggers separately, and observing a trend of a positive association in the risk ratios, but suspecting lack of power due to the relatively small cohort. 


\section{Summary \& Conclusion}

In this case-crossover study on preceding events before ICH onset, we found that physical triggers i.e. factors that raise blood pressure abruptly associate with the timing of $\mathrm{ICH}$, potentially serving as triggering factors of $\mathrm{ICH}$. Only one third of the patients could be interviewed and provide consistent answers to the trigger questions. Future studies with larger cohorts are needed to confirm our results and to examine, whether there are differences between the strength of association between the physical triggers.

\section{Declarations of interests}

J.P. reports personal fees from Boehringer-Ingelheim, personal fees from Bayer, grants and personal fees from BMS-Pfizer, grants and personal fees from Abbott/St. Jude Medical, Research collaboration, and stock ownership from Vital Signum, research collaboration from Nokia Technologies, research collaboration from Bittium, research collaboration from BcB Medical, personal fees from Portola, personal fees from Terve Media, grants from Business Finland, grants from Amgen, outside the submitted work; and he has participated in the European Stroke Organisation's guideline working groups on (1) Post-stroke hyperglycemia and (2) Secondary prevention in patients with AF. He also has participated in the Finnish Duodecim Society's guideline working group on Ischemic stroke and TIA. H.S. reports grants from Maire Taponen Foundation, Biomedicum Helsinki Foundation, and The Finnish Medical Foundation. D.S. reports no conflicting interests. 


\section{Acknowledgements}

This work was supported by Helsinki University Hospital Research Funds, funds from Maire Taponen Foundation, Biomedicum Helsinki Foundation, and The Finnish Medical

Foundation. J.P. reports grants from BMS-Pfizer, Abbott/St. Jude Medical, and Business Finland.

\section{Funding}

This study was supported by Helsinki University Hospital Research Funds, funds from Maire Taponen Foundation, Biomedicum Helsinki Foundation, and The Finnish Medical Foundation. 


\section{References}

1. Feigin VL, Lawes CM, Bennett DA, et al. Worldwide stroke incidence and early case fatality reported in 56 population-based studies: a systematic review. Lancet Neurology. 2009;8:355-369.

2. van Asch CJ, Luitse MJ, Rinkel GJ, et al. Incidence, case fatality, and functional outcome of intracerebral haemorrhage over time, according to age, sex, and ethnic origin: a systematic review and meta-analysis. Lancet Neurology. 2010;9:167-176.

3. Hemphill CJ, Greenberg SM, Anderson CS, et al. Guidelines for the Management of Spontaneous Intracerebral Hemorrhage. Stroke. 2015;46:2032-2060.

4. O’Donnell MJ, Chin S, Rangarajan S, et al. Global and regional effects of potentially modifiable risk factors associated with acute stroke in 32 countries (INTERSTROKE): a case-control study. Lancet. 2016;388:761-775.

5. Ariesen M, Claus S, Rinkel JEG, et al. Risk Factors for Intracerebral Hemorrhage in the General Population. Stroke. 2003;34:2060-2065.

6. Vlak M, Rinkel G, Greebe P, et al. Trigger Factors and Their Attributable Risk for Rupture of Intracranial Aneurysms. Stroke. 2011;42:1878-1882.

7. Vlak MH, Rinkel GJ, Greebe P,et al. Trigger factors for rupture of intracranial aneurysms in relation to patient and aneurysm characteristics. Journal of Neurology. 2011;259:1298-1302.

8. Mostofsky E, Laier E, Levitan EB,et al. Physical Activity and Onset of Acute Ischemic Stroke The Stroke Onset Study. American Journal of Epidemiology. 2011;173:330-336. 9. Koton S, Tanne D, Bornstein N, et al. Triggering risk factors for ischemic stroke: a case-crossover study. Neurology. 2004;63:2006-2010. 
10. Ducros A, Boukobza M, Porcher R,et al. The clinical and radiological spectrum of reversible cerebral vasoconstriction syndrome. A prospective series of 67 patients. Brain. 2007;130:3091-3101.

11. Foreman PM, Griessenauer CJ, Selim MH, et al. Sexual activity as a trigger for intracranial hemorrhage. Acta Neurochirurgica. 2016;158:189-195.

12. Maclure M, Mittleman M. Should we use a case-crossover design? Annual Review of Public Health. 2000;21:193-221.

13. Mittleman M, Maclure M, Tofler G, et al. Triggering of acute myocardial infarction by heavy physical exertion. Protection against triggering by regular exertion.

Determinants of Myocardial Infarction Onset Study Investigators. New England Journal of Medicine. 1993;329:1677-1683.

14. Petridou E, Mittleman MA, Trohanis D, et al. Transient Exposures and the Risk of Childhood Injury. Epidemiology. 1998;9:622-625.

15. Mittleman MA, Mostofsky E. Exchangeability in the case-crossover design. International Journal of Epidemiology. 2014;43:1645-1655.

16. Passero S, Ciacci G, Reale F. Potential Triggering Factors of Intracerebral Hemorrhage. Cerebrovascular Diseases. 2001;12:220-227.

17. Anderson C, Mhurchu C, Scott D, et al. Triggers of Subarachnoid Hemorrhage. Stroke. 2003;34:1771-1776.

18. Littler W, Honour A, Sleight P. Direct Arterial Pressure, Heart Rate and Electrocardiogram During Human Coitus. Reproduction. 1974;40:321-331.

19. Pott F, Lieshout JJ, Ide K, et al. Middle cerebral artery blood velocity during intense static exercise is dominated by a Valsalva maneuver. Journal of Applied Physiology. 
2003;94:1335-1344.

20. Tiecks FP, Lam AM, Matta BF, et al. Effects of the Valsalva Maneuver on Cerebral Circulation in Healthy Adults. Stroke. 1995;26:1386-1392.

21. Weiss SA, Blumenthal RS, Sharrett RA, et al. Exercise Blood Pressure and Future Cardiovascular Death in Asymptomatic Individuals. Circulation. 2010;121:2109-2116.

22. Mittleman M, Maclure M, Sherwood J, et al. Triggering of Acute Myocardial Infarction Onset by Episodes of Anger. Circulation. 1995;92:1720-1725.

23. Mittleman MA, Mostofsky E. Physical, Psychological and Chemical Triggers of Acute Cardiovascular Events. Circulation. 2011;124:346-354.

24. Muller JE, Mittleman MA, Maclure M, et al. Triggering Myocardial Infarction by Sexual Activity: Low Absolute Risk and Prevention by Regular Physical Exertion. JAMA. 1996;275(18):1405-9.

25. Hallqvist J, Moller J, Ahlbom A, et al. Does Heavy Physical Exertion Trigger Myocardial Infarction?: A Case-Crossover Analysis Nested in a Population-based Casereferent Study. Am J Epidemiol. 2000;151(5):459-67. 
Figure legends

Figure 1. Patient selection flowchart 


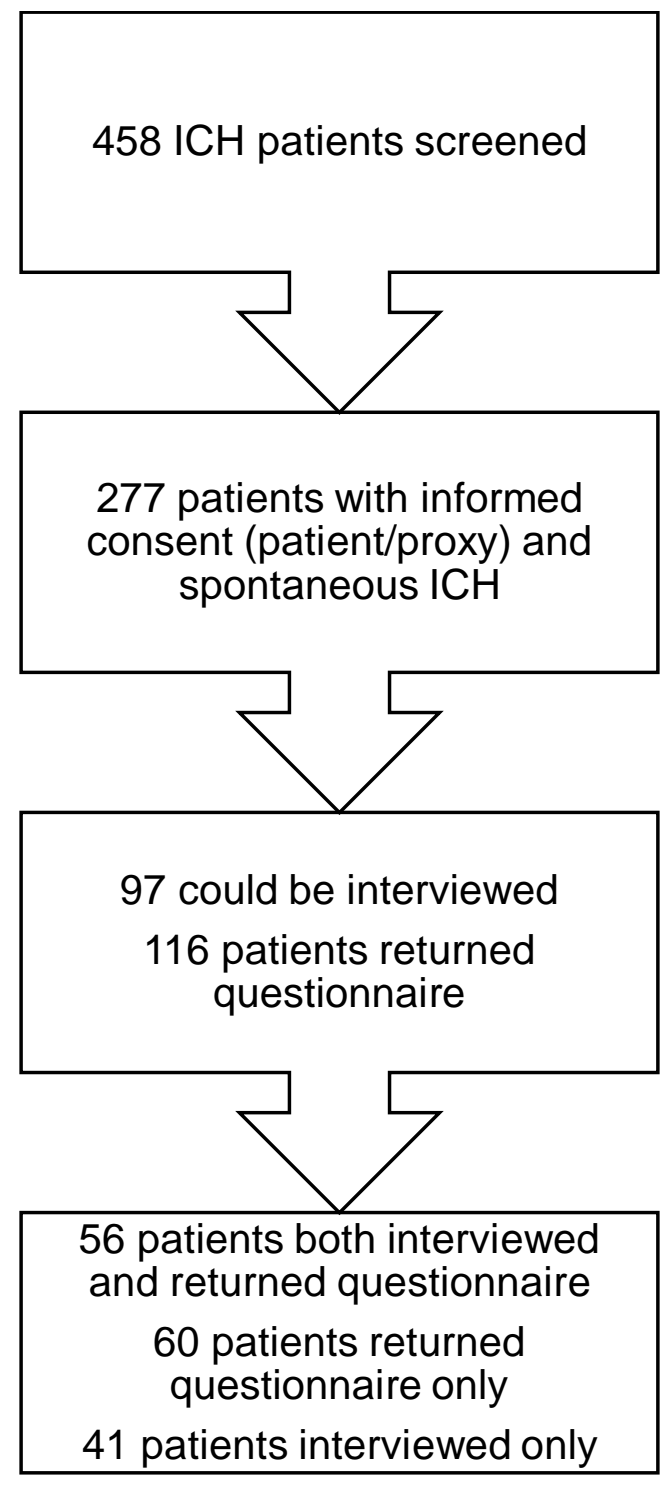




\section{Tables}

Table 1. Comparison of the characteristics between patients with $(n=97)$ and without trigger data $(n=180)$

\begin{tabular}{|c|c|c|c|}
\hline Variable & $\begin{array}{l}\text { Included in trigger } \\
\text { questioning }(\mathrm{N}=97)\end{array}$ & $\begin{array}{l}\text { Not included in } \\
\text { trigger questioning } \\
(\mathrm{N}=180)\end{array}$ & P Value \\
\hline Age, y & $66.0(57.0-74.5)$ & $73.5(63.3-80.0)$ & $<0.001$ \\
\hline Male & $54(55.7)$ & $101(56.1)$ & 0.944 \\
\hline Consent given by proxy & $7(7.2)$ & $106(58.9)$ & $<0.001$ \\
\hline History of hypertension & $67(69.1)$ & $122(67.8)$ & 0.825 \\
\hline Diabetes & $8(8.2)$ & $36(20.0)$ & 0.011 \\
\hline History of ischemic stroke & $8(8.2)$ & $21(11.7)$ & 0.375 \\
\hline History of any ICH & $4(4.1)$ & $16(8.9)$ & 0.144 \\
\hline COPD or asthma & $9(9.3)$ & $15(8.3)$ & 0.790 \\
\hline Dementia & $2(2.1)$ & $12(6.7)$ & 0.149 \\
\hline Coronary artery disease & $7(7.2)$ & $23(12.8)$ & 0.155 \\
\hline Atrial fibrillation & $16(16.5)$ & $47(26.1)$ & 0.069 \\
\hline Chronic heart failure & $5(5.2)$ & $12(6.7)$ & 0.617 \\
\hline Antiplatelet treatment ${ }^{\mathrm{a}}$ & $15(15.5)$ & $50(28.1)$ & 0.019 \\
\hline Anticoagulant treatment & $14(14.4)$ & $42(23.3)$ & 0.078 \\
\hline Antihypertensive medication ${ }^{\mathrm{a}}$ & $47(48.5)$ & $97(54.5)$ & 0.338 \\
\hline NIHSS on admission ${ }^{\mathrm{a}}$ & $5.0(2.0-11.0)$ & $12.0(4.0-18.8)$ & $<0.001$ \\
\hline GCS on admission & $15.0(15.0-15.0)$ & $14.0(12.0-15.0)$ & $<0.001$ \\
\hline Baseline ICH volume, $\mathrm{mL}$ & $6.9(2.2-13.6)$ & $19.1(8.0-48.0)$ & $<0.001$ \\
\hline ICH location & & & 0.005 \\
\hline ICH location, lobar & $18(18.6)$ & $64(35.6)$ & \\
\hline
\end{tabular}




\begin{tabular}{|c|c|c|c|}
\hline $\begin{array}{l}\text { ICH location, deep } \\
\text { supratentorial }\end{array}$ & $71(73.2)$ & $96(53.3)$ & \\
\hline ICH location, infratentorial & $8(8.2)$ & $17(9.4)$ & \\
\hline ICH location, mixed & $0(0.0)$ & $3(1.7)$ & \\
\hline $\begin{array}{l}\text { Deterioration (increase in } \\
\text { NIHSS at least } 4 \text { points) } \\
\text { within } 1 \text { week of ICH }\end{array}$ & $5(5.2)$ & $50(27.8)$ & $<0.001$ \\
\hline Any neurosurgery & $1(1.0)$ & $11(6.1)$ & 0.048 \\
\hline DNR orders in hospital & $7(7.2)$ & $72(40.0)$ & $<0.001$ \\
\hline $\mathrm{mRS}$ at 3 months $^{\mathrm{a}}$ & & & $<0.001$ \\
\hline mRS 0 & $3(3.1)$ & $6(3.4)$ & \\
\hline mRS 1 & $11(11.3)$ & $7(3.9)$ & \\
\hline $\mathrm{mRS} 2$ & $44(45.4)$ & $37(20.7)$ & \\
\hline mRS 3 & $18(18.6)$ & $22(12.3)$ & \\
\hline $\mathrm{mRS} 4$ & $7(7.2)$ & $31(17.3)$ & \\
\hline $\mathrm{mRS} 5$ & $11(11.3)$ & $23(23.8)$ & \\
\hline mRS 6 & $3(3.1)$ & $53(29.6)$ & \\
\hline mRS $0-2$ at 3 months & $58(59.8)$ & $50(27.9)$ & $<0.001$ \\
\hline Barthel Index at 3 months ${ }^{\mathrm{a} b}$ & $100.0(90.0-100.0)$ & $95.0(47.5-100.0)$ & 0.009 \\
\hline Living at home at 3 months ${ }^{\mathrm{a} b}$ & $74(78.7)$ & $74(59.2)$ & 0.002 \\
\hline
\end{tabular}

Data are n (\%), mean (SE), or median (IQR)

Abbreviations: mRS, modified Rankin Scale; ICH, intracerebral hemorrhage; COPD, chronic obstructive pulmonary disease; NIHSS, the National Institutes of Health Stroke Scale; DNR, do not resuscitate

${ }^{\text {a }}$ Missing data for antiplatelet treatment in 2 patients $(0.007 \%)$, antihypertensive medication in 2 patients $(0.007 \%)$, NIHSS on admission in 7 patients $(0.03 \%)$, mRS at 3 months in 1 patient 
$(0.004 \%)$, Barthel Index at 3 months in 1 patient $(0.005 \%)$, living at home at 3 months in 1 patient $(0.005 \%)$

${ }^{\mathrm{b}}$ Barthel Index at 3 months, and living at home at 3 months percentages of alive patients $(\mathrm{N}=220)$

Table 2. Relative risks for the exposures of potential trigger factors during the 2 hour period preceding the ICH, compared to the same period the day before.

\begin{tabular}{|c|c|c|c|c|c|c|c|}
\hline $\begin{array}{l}\text { Triggering } \\
\text { factor }\end{array}$ & $\begin{array}{l}\text { Number } \\
\text { of } \\
\text { included } \\
\text { patients }\end{array}$ & $\begin{array}{l}\text { Exposed } \\
\text { in the } \\
\text { hazard } \\
\text { period }\end{array}$ & $\begin{array}{l}\text { The day } \\
\text { of the ICH } \\
\text { only (only } \\
\text { in the } \\
\text { hazard } \\
\text { period) }\end{array}$ & $\begin{array}{l}\text { The day } \\
\text { before } \\
\text { only }\end{array}$ & $\begin{array}{l}\text { Both } \\
\text { periods }\end{array}$ & $\begin{array}{l}\text { No } \\
\text { exposure } \\
\text { on either } \\
\text { time } \\
\text { period }\end{array}$ & $\begin{array}{l}\text { RR }(95 \% \\
\text { CI) }\end{array}$ \\
\hline $\begin{array}{l}\text { Physical } \\
\text { trigger } \\
\text { (Valsalva, } \\
\text { heavy exercise, } \\
\text { sex) }\end{array}$ & 96 & 41 & 17 & 7 & 24 & 48 & $\begin{array}{l}1.32(1.01, \\
1.73)\end{array}$ \\
\hline Valsalva & 78 & 23 & 7 & 4 & 16 & 51 & $\begin{array}{l}1.15(0.85, \\
1.56)\end{array}$ \\
\hline Heavy exercise & 95 & 13 & 6 & 2 & 7 & 80 & $\begin{array}{l}1.44(0.87, \\
2.41)\end{array}$ \\
\hline Sex & 88 & 5 & 4 & 3 & 1 & 80 & $\begin{array}{l}1.25(0.39, \\
3.99)\end{array}$ \\
\hline
\end{tabular}




\begin{tabular}{|c|c|c|c|c|c|c|c|}
\hline $\begin{array}{l}\text { Change in } \\
\text { position (such } \\
\text { as startling) }\end{array}$ & 94 & 0 & 0 & 0 & 0 & 94 & NA \\
\hline Heavy meal & 93 & 2 & 2 & 4 & 0 & 87 & $\begin{array}{l}0.50 \\
(0.092, \\
2.73)\end{array}$ \\
\hline $\begin{array}{l}\text { Change in } \\
\text { temperature }\end{array}$ & 94 & 4 & 2 & 4 & 2 & 86 & $\begin{array}{l}0.67(0.25, \\
1.78)\end{array}$ \\
\hline $\begin{array}{l}\text { Exposure to } \\
\text { traffic }\end{array}$ & 95 & 5 & 3 & 4 & 2 & 86 & $\begin{array}{l}0.83(0.32, \\
2.15)\end{array}$ \\
\hline
\end{tabular}

